\title{
UNIDADES DE PAISAJE DEL VALLE DEL ANDARAX (PROVINCIA DE ALMERÍA)
}

\author{
EMiLio FERRE Bueno
}

\begin{abstract}
RESUMEN
Este trabajo presenta la delimitación y caracterización de unidades de paisaje en el Valle del Andarax (provincia de Almería) que abarca sistemas de tierras distintas (montaña, piedemonte y valle). Se ha trabajado a escala 1:50.000 mediante la superposición con ArcGIS de mapas temáticos referentes a topografía, litología, morfometría, geomorfología y vegetación. Las unidades resultantes son útiles para el manejo de un territorio afectado por la desertificación.
\end{abstract}

\section{ABSTRACT}

This article deals with the delimitation and caracterization of landscape units in the Andarax Valley (Almeria area) which includes various terrain systems (mountain, piedmont and valley). We have worked on a 1: 50.000 scale by the superposition of theme maps referring to topography, lithology, morphometry, geomorphology and vegetation. The resulting units are helpful to handle a territory affected by dessertification.

\section{INTRODUCCIÓN}

El paisaje geográfico se articula como el fundamento de unos sistemas de relaciones entre los elementos del medio físico y los grupos humanos que, organizados, viven el él, lo ordenan y lo elaboran. El paisaje es concebido como forma que obedece al funcionamiento de un sistema y comporta una serie de elementos visibles (relieves, vegetación, redes fluviales, campos de cultivos, hábitat, etc.) y unos factores no perceptibles a simple vista, pero que forman un sistema de relaciones territoriales que el geógrafo, con su razonamiento espacial para interpretar la heterogeneidad que subyace en todo paisaje, es capaz de establecer. El geógrafo debe hacer "visibles" los paisajes mostrando sus potencialidades y posibilidades de evolución, así como transmitir su 
valor patrimonial. Del mismo modo, cualquier planificación territorial con el objetivo de organizar y de estructurar un espacio debe basarse en el profundo conocimiento del territorio que se va a manejar.

En este somero marco conceptual se sitúa el contenido de este trabajo, que tiene por objeto delimitar y describir en un territorio distintas unidades espaciales que por sus atributos intrínsecos, fisiográficos, biogeográficos y morfogenéticos, se distinguen entre sí y pueden ser útiles para el manejo de este espacio afectado por la desertificación.

\section{METODOLOGÍA}

Se ha utilizado el nivel de aproximación a los sistemas de tierras (Verstapen y Van Zuidam, 1991) para distinguir siete sistemas de tierras diferentes por sus elementos estructurales, topográficos, morfológicos, biogeográficos y morfogenéticos. La delimitación se ha hecho según el concepto de sistemas de tierras (Van Zuidam y Van Zuidam-cancelado,1979), que se fundamenta en unidades homogéneas (Christian y Stewart, 1958), largamente utilizado hasta la actualidad (Francés, et al., 1989; Cendrero, et al., 1986; Díaz De Terán, et al., 1991, Ferre Bueno, et al., 1994; Ferre Bueno, 1997). Los sistemas de tierras obtenidos se refieren a formas de relieve, de modelado y a formaciones vegetales consideradas a escala 1:50.000 y cada uno de ellos presenta características externas e internas distintas de los sistemas de alrededor.

El procedimiento para su delimitación ha sido la elaboración de mapas temáticos que conciernen a la morfoestructura, litología, morfometría, morfología, morfogénesis y formaciones vegetales y la superposición de los mismos mediante ArcGIS.

La base cartográfica utilizada corresponde a los mapas topográficos de Servicio Geográfico del Ejército y a los mapas geológicos y sus memorias del I.G.M.E a escala 1:50.000, de las Hojas: 1043 (Berja), 1044 (Alhama de Almería),1045 (Almería), 1059 (El Cabo de Gata),1029 (Gérgal) y 1030 (Tabernas), rectificadas con trabajo de campo.

Los mapas morfométricos se han elaborado a partir de los mapas topográficos a escala 1:50.000 y los mapas geomorfológicos se han elaborado con fotografía aérea a escala 1:20.000 (vuelo de nov. 1989), trabajo de campo y restitución con los mapas topográficos a escala 1:50.000. La información de la vegetación esta tomada del trabajo de investigación "Estudio fitosociológico integral, modelos de evaluación biológica y restauración de la vegetación en un territorio amenazado por la desertificación. Cuenca del río Andarax (Almería, España)", becado por la fundación "Ramon Areces", realizado por un equipo multidisciplinar de las universidades de Málaga y Granada, del que he formado parte (Díaz Garretas et al., 1996). 


\section{RASGOS GENERALES Y CRITERIOS DE DELIMITACIÓN}

El Valle del Andarax se localiza en el centro-sur de la provincia de Almería, con una disposición oeste-este en sus dos terceras partes y con un cambio hacia la orientación noroeste-sureste en el último tramo de su recorrido (fig. 1). La cuenca hidrográfica tiene una extensión de $2.187,6 \mathrm{~km}^{2}$ y recibe el nombre del elemento fluvial que jerarquiza su drenaje: el río Andarax. Tiene su nacimiento en el cerro del Almirez a $2.512 \mathrm{~m}$ de altura, en el extremo oriental de las estribaciones de Sierra Nevada y, tras un recorrido de 66,6 km, desemboca en el Mediterráneo al este de la ciudad de Almería.

La red hidrográfica del río Andarax drena la depresión estructural delimitada, al sur, por la sierra de Gádor y, al norte, por las estribaciones orientales de Sierra Nevada y el tramo central de la sierra de los Filabres. La incorporación por la margen izquierda de tributarios importantes como el río Nacimiento, la rambla de Gérgal y la de Tabernas le imprimen al río Andarax una inflexión hacia el sur, de tal manera que el último tramo de su recorrido lo hace atravesando un pasillo estructural abierto entre el extremo oriental de la sierra de Gádor, al oeste, y el extremo occidental de la sierra de Alhamilla, al este.

Mientras que las sierras limítrofes son altas montañas que superan los $2.000 \mathrm{~m}$ de altitud, las tierras del valle ocupan una depresión, rellena con sedimentos marinos, dispuesta entre las sierras antes citadas. La red fluvial se ha encajado con energía y ha provocado un modelado de cárcavas y barrancos que dejan entre sí un dédalo de colinas cuyas cumbres oscilan entre los $800 \mathrm{~m}$ de altitud en le valle alto y los $100 \mathrm{~m}$ en el valle bajo.

Los caracteres climáticos varían entre la cuenca alta y el valle bajo y medio. En la primera, las precipitaciones, siempre irregulares, pueden alcanzar cifras importantes en el extremo occidental de la sierra de Gádor $(500-650 \mathrm{~mm}$ al año) y en el extremo oriental de Sierra Nevada (1.280 mm, Laujar- Monterrey) ; pero en el fondo del valle disminuyen ( $253 \mathrm{~mm}$, Alhama de Almería) y a medida que nos desplazamos hacia el valle bajo las precipitaciones se hacen aún más escasas (221 mm, Tabernas; $208 \mathrm{~mm}$, Almería), donde la aridez es tan evidente que desde las últimas décadas se viene utilizando, con marcada intención turística, el topónimo de Desierto de Tabernas para designar un territorio que, tradicionalmente, se ha llamado Campo de Tabernas.

Las temperaturas son moderadas en general, aunque también es manifiesta una gradación térmica desde la zona oriental, más cálida, hasta la occidental, más templada, y desde el fondo del valle hasta las cumbres de las sierras. Así en el valle bajo la temperatura media anual supera $\operatorname{los} 18^{\circ} \mathrm{C}$, en el valle medio oscila entre $16-18^{\circ} \mathrm{C}$, en la cabecera de la cuenca es de $14^{\prime} 5^{\circ} \mathrm{C}$ y en las sierras es de $10^{\prime} 2^{\circ} \mathrm{C}$. Los inviernos llegan a ser fríos en la cabecera de la 

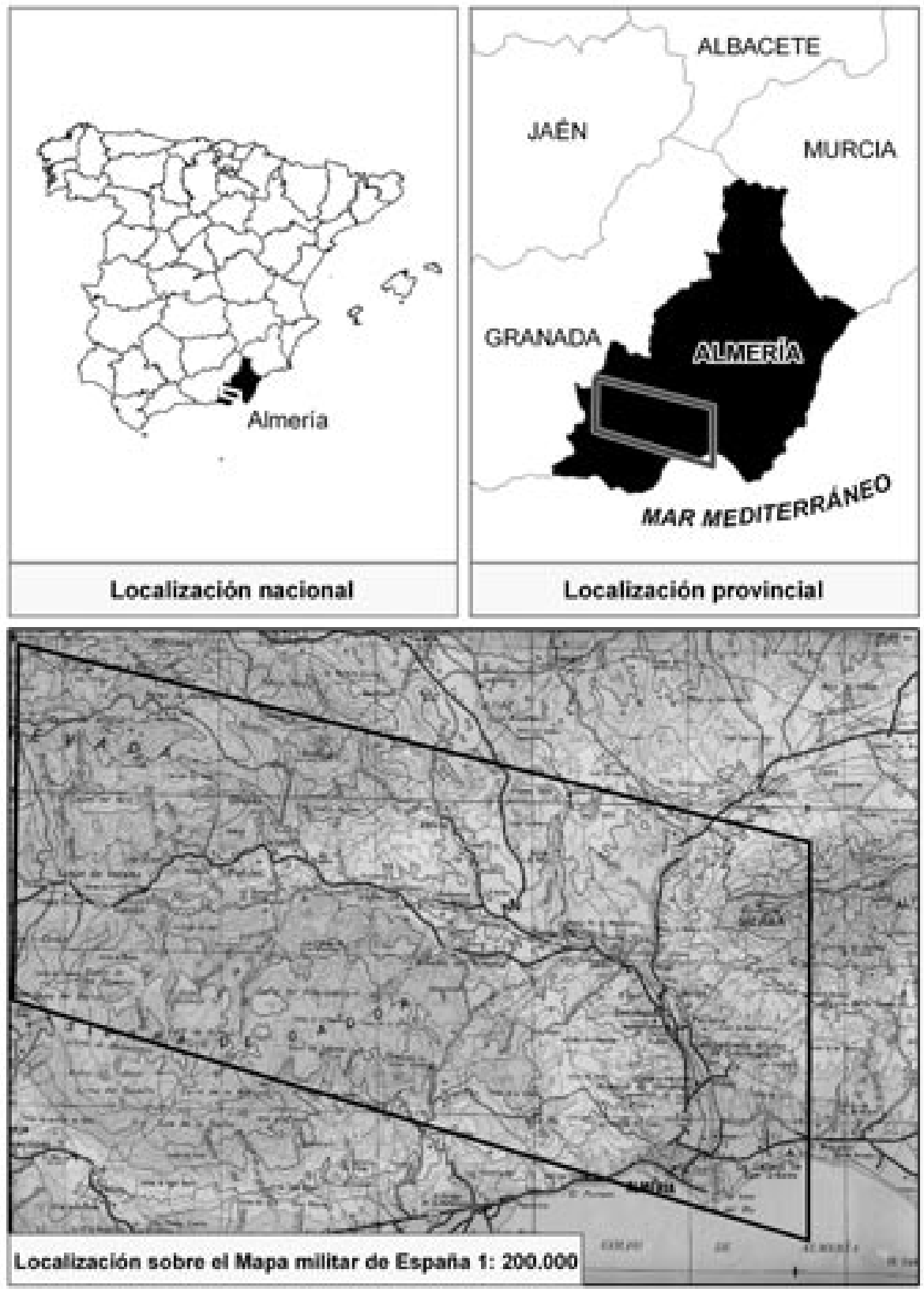

1. Situación del valle del río Andarax 
cuenca y en las sierras; mientras que los veranos en el valle bajo son los más calurosos de toda la provincia de Almería.

Siguiendo la caracterización bioclimática de Rivas Martínez (1995) el clima de este territorio es mediterráneo y presenta al menos dos meses secos en verano. Entre los siete bioclimas que se reconocen en el macrobioclima mediterráneo, las zonas montanas que comprenden las sierras de Gádor, Nevada y Alhamilla, a partir de los $800 \mathrm{~m}$ de altitud, presentan un bioclima de tipo pluviestacional-oceánico, correspondiéndole un vegetación potencial de bosques perennifolios (Quercetea ilicis) o aciculifolios (Pino-Juniperetea); mientras que las zonas de las sierras por debajo de esta cota, además del valle del Andarax y el Campo de Tabernas, presentan un biocloma xérico-oceánico, correspondiendo la vegetación potencial a distintos tipos de formaciones arbustivas espinosas pertenecientes a Pistacio-Rhamnetalia alaterni. Según los índices bioclimáticos utilizados en dicha caracterización en el territorio estudiado aparecen los pisos bioclimáticos que van desde el oromediterráneo, en las cumbres de la sierra de Gádor y de la parte oriental de Sierra Nevada, hasta el termomediterráneo inferior, en el delta del río Andarax, pasando por los pisos supramediterráneo y mesomediterráneo, ampliamente representados. En el cuadrio $n^{\circ} 1$ se reflejan las estaciones meteorológicas más representativas con los valores de los distintos parámetros necesarios para delimitar los pisos bioclimáticos (Rivas Martínez, 1995) .

El río Andarax tiene un comportamiento hidrológico que se enmarca en las características de los ríos del sureste de la Península Ibérica, como son su alimentación fundamentalmente pluvial (si bien este río participa algo de los deshielos de las cumbres de Sierra Nevada durante un mes aproximadamente, por lo que se podría hablar de una alimentación pluvio-nival), su régimen irregular, con largos estiajes, que en las últimas décadas duran casi todo el año, y crecidas espasmódicas, especialmente en otoño, con frecuentes consecuencias catastróficas. El diseño de la red hidrográfica tiende a un patrón dendrítico (del griego dendros = árbol) ; aunque en ciertas áreas los condicionantes tectónicos introducen patrones subdendríticos y hasta subparalelos. 


\section{CUADRO 1 \\ VALORES TERMOPLUVIOMÉTRICOS Y PISOS BIOCLIMÁTICOS DEL VALLE DEL ANDARAX}

\begin{tabular}{|l|c|c|c|c|c|c|c|c|}
\hline Estación & Altitud & T & P & It & Ic & Itc & Termotipo & Ombroclima \\
\hline Laujar-Cerecillo & 1800 & $10^{\prime} 2$ & 1800 & 124 & $15^{\prime} 7$ & 178 & Supramediterráneo & Subhúmedo \\
\hline Laujar- Monterrey & 1280 & $12^{\prime} 9$ & 1280 & 254 & $16^{\prime} 2$ & 254 & Mesomediterráneo & Subhúmedo \\
\hline Alhama-la Zarba & 1219 & & 456 & & & & Mesomediterráneo & Seco \\
\hline Ohanes & 1000 & & 1000 & & & & Mesomediterráneo & Seco \\
\hline Laujar & 921 & $14^{\prime} 5$ & 921 & 300 & $15^{\prime} 8$ & 300 & Mesomediterráneo & Subhúmedo \\
\hline Canjáyar-Cristal & 800 & $17^{\prime} 3$ & 800 & 387 & $12^{\prime} 0$ & 387 & Termomediterráneo & Semiárido \\
\hline Canjáyar & 610 & $17^{\prime} 8$ & 600 & 392 & $17^{\prime} 3$ & 392 & Termomediterráneo & Semiárido \\
\hline Nacimiento & 595 & & 213 & & & & Termomediterráneo & Semiárido \\
\hline Alhama de Almería & 520 & & 253 & & & & Termomediterráneo & Semiárido \\
\hline Alboloduy & 460 & & 231 & & & & Termomediterráneo & Semiárido \\
\hline Tabernas & 221 & $17^{\prime} 9$ & 221 & & $16^{\prime} 2$ & 393 & Termomediterráneo & Semiárido \\
\hline Almería Aeropuerto & 21 & $18^{\prime} 5$ & 189 & & $13^{\prime} 6$ & 434 & Termomediterráneo & Semiárido \\
\hline Almería & 7 & $18^{\prime} 2$ & 208 & & $13^{\prime} 4$ & 426 & Termomediterráneo & Semiárido \\
\hline
\end{tabular}

Leyenda: $\mathbf{T}=$ Temperatura media anual $\mathbf{P}=$ Precipitación media anual $\mathbf{I t}=$ Índice de termicidad $=(\mathbf{T}+\mathbf{M}+\mathbf{m}) \mathbf{1 0} . \mathbf{M}=$ Temperatua media de las máximasdel mes más frío; $\mathbf{m}=$ Temperatura media de las mínimas del mes más frío; Ic = Índice de continentalidad atenuado, es la diferencia entre las temperaturas, en grados centígrados, del mes más cálido y el mes más frío del año; Itc = Índice de termicidad compensado, es igual a It sumándole o restándole un factor de compensación $\mathbf{C}$ calculado a partir de Ic.

Fuente: Díaz Garretas, et al., 1996.

El criterio de delimitación del área de trabajo ha sido abarcar toda la cuenca hidrográfica, excluyendo aquellos territorios que significan unidades de paisaje repetitivas, que sólo aportarían mayor extensión superficial al estudio pero no más diversidad en los fenómenos que se tratan de investigar. Este es el caso de la sierra de los Filabres, en su flanco sur, cuyos rasgos paisajísticos y cuya problemática fitocenótica es similar a las de las estribaciones orientales de Sierra Nevada. Igual sucede con su piedemonte, cuyas características se repiten en el flanco norte de Sierra Nevada. Por ello, si por el sur, este y oeste los límites del área analizada coinciden con las divisorias de aguas naturales de la cuenca hidrográfica, por el norte, el límite se ha establecido de tal manera que queden excluidas las superficies correspondientes a la sierra de los Filabres y su piedemonte y parte de la rambla de Tabernas. Estas exclusiones no cercenan, en absoluto, ninguna unidad de paisaje que aporte diversidad e interés al conjunto de la investigación, obtieniéndose una superficie del área estudiada de $99.000 \mathrm{Ha}$. 


\section{LAS UNIDADES DE PAISAJE}

En la cuenca del río Andarax se pueden distinguir las siguientes unidades de paisaje, basadas en las características de sus formas de relieve estructural, en sus formas de modelado y en las formaciones vegetales: el extremo oriental de Sierra Nevada, la sierra de Gádor, la sierra de Alhamilla, los piedemontes, el sistema de cárcavas de la cuenca sedimentaria neógena del Andarax, el sistema de terrazas aluviales del río Andarax y el delta del río Andarax (fig. 2).

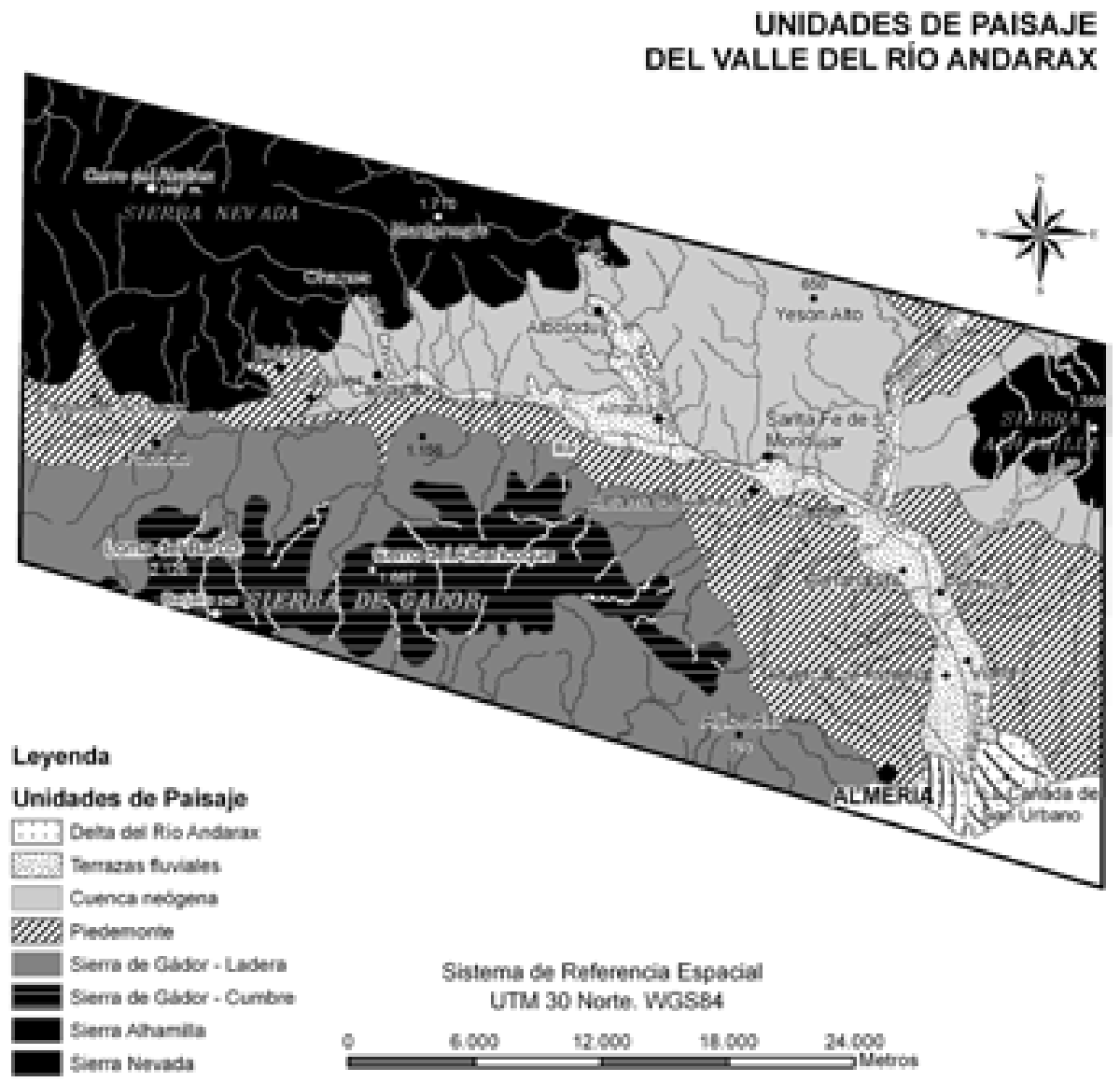

2. Unidades de paisaje del valle del río Andarax 


\subsection{Sierra Nevada}

Está representada por su extremo más oriental, que pertenece a la provincia de Almería, y que aquí se nombra por sierra de Laujar, sierra de Beires, sierra de Ohanes y Montenegro, separadas por profundas gargantas de barrancos y ramblas como los barrancos de Benecid, Beires, Ohanes o la rambla de Tices. La superficie es de 25.626 Ha que significan el 25,8\% del total del área estudiada. Es una alta montaña cuyas cumbres superan los $2.000 \mathrm{~m}$ (cerro del Almirez $2.512 \mathrm{~m}$; La Polarda $2.552 \mathrm{~m}$ ), aunque hacia el este se rebaja la altitud (Montenegro $1.710 \mathrm{~m}$ ). Los desniveles relativos con las depresiones circundantes (cabecera del río Andarax y cabecera del río Nacimiento) sobrepasan los $1.000 \mathrm{~m}$. Sin embargo el aspecto de la sierra es el de enormes macizos alomados en los que predominan las laderas convexas que no trasmiten la percepción de alta montaña abrupta.

Ello se debe a su constitución geológica, ya que Sierra Nevada está formada por un apilamiento de mantos de corrimiento pertenecientes al complejo Nevado-Filábride y constituidos, fundamentalmente, por micasquistos y gneises plegados en una gran bóveda anticlinal y rodeados por una aureola de dolomías y mármoles dolomíticos. La litología silícea (micasquistos y gneises) presenta mediana resistencia a la erosión que, junto al hecho de que las cumbres de la sierra presenten vestigios de una antigua superficie de erosión finimiocena, se conjugan para configurar el aspecto alomado de este conjunto montañoso cuyas laderas tienen pendientes que oscilan entre el 55 y el $80 \%$.

Sólo la erosión fluvial, que ha abarrancado profundamente los flancos de la sierra, en los que afloran las dolomías o los mármoles, y los frecuentes núcleos de gneises cuarcíticos, más resistentes a la erosión que los micasquistos, son responsables de morfologías abruptas en forma de profundas gargantas, en el caso de los torrentes, o como relieves residuales formando crestas y pitones, en el caso de los afloramientos gnéisicos y dolomíticos.

Por el flanco norte Sierra Nevada conecta con la cabecera del río Nacimiento mediante un piedemonte constituido por una superficie suavemente inclinada, que corresponde con la cubierta de un glacis-cono del Cuaternario antiguo que termina, hacia abajo, sobre dos niveles de terrazas fluviales elaboradas por el río Nacimiento. Por el flanco sur la mole de la sierra termina hundiéndose en la cuenca sedimentaria neógena mediante un piedemonte de transición. Los tintes de las rocas de este macizo montañoso, en una gama que va del violáceo al negro, le dan a todo el conjunto una coloración tan oscura que explica algunas topónimos como el de "Montenegro" en el extremo más avanzado de la sierra hacia el levante.

En Sierra Nevada existe gradación de la vegetación a causa de las variaciones climáticas en altitud. Por encima de los 1.800-2.000 m está el piso 
oromediteráneo al que corresponde una vegetación potencial de enebrales de la que, actualmente, sólo hay una vegetación serial formada por espinares compuestos por Crataegus monogyna, Prunus ramburii, Rosa nitidula, Rosa stylosa, Rosa pouzini, Berberis hispanica, y piornales cuyas especies dominantes son la Genista versicolor, en los suelos más potentes, y el Ciytisus oromediterraneus en los menos desarrollados. Mezcladas con estos matorrales espinosos aparecen especies propias del pastizal o tomillar como Festuca indigesta, Deschampsia flexulosa, Tymus serpylloides, que se hacen dominantes en extensas zonas manejadas por el hombre, mediante el fuego y el pastoreo, y en la zona de cumbres como vegetación serial de lo que pudieron ser los antiguos enebrales. Amplias zonas se han repoblado con pinares en los que se ha utilizado mayoritariamente el Pinus sylvestris; aunque en las zonas más elevadas (hasta los $2.300 \mathrm{~m}$ ) se ha utilizado el Pinus uncinata. La cobertura de estos pinares es diversa, habiendo zonas aclaradas en las que dominan los matorrales mientras que en topografías más suaves domina el pinar con bastante densidad y grado de madurez.

Entre 1.500 y $2.000 \mathrm{~m}$ está el piso supramediterráneo, cuya vegetación potencial se compone de encinares de Quercus rotundifolia con espinares, actualmente representada sólo por espinares, con espino blanco y rosales, semejantes a los del piso superior, salviares y tomillares con Salvia lavandulifolia, Lavandula lanata, Echinospartum boissieri, Teucrium webbianum, Buplerum spinosum, salpicados de retamares cuyas especies directrices son el Cytisus reverchonii y la Genista cinerea. En algunas zonas, como en Montenegro y en la sierra de Ohanes, quedan restos bien conservados de encinar adehesado. Además hay amplias extensiones de pinares de repoblación a base de Pinus nigra, Pinus pinaster y Pinus halepensis.

El piso mesomediterráneo abarca desde los $800 \mathrm{~m}$ a $\operatorname{los} 1.600 \mathrm{~m}$ y su vegetación potencial también es un encinar de Quercus rotundifolia. En las zonas más altas del piso se presenta en forma de encinares abiertos mezclados con etapas de sustitución en las que dominan los jarales (Cistus laurifolius, Cistus salvifolius, Halimium viscosum, Lavandula stoechas, Tymus mastichina, etc.), lastonares (Festuca scariosa, Festuca elegans, Dactylis glomerata), escobonales con Adenocarpus decorticans, Genista florida, Genista cinerea y Cytisus scoparius, y extensas manchas de tomillar-pastizal con Erinacea anthyllis, Thymus serpylloides, Phlomis crinita, Festuca indigesta, Deschampsia flexulosa, etc.. Un poco más abajo se desarrollan encinares en buen estado, que llegan a tener más del 60\% de cobertura, mezclados con retamar (Adenocarpus decorticans, Retama sphaerocarpa) y bolinar con Genista umbellata, Lavandula stoechas, Paronychia suffruticosa, Thymus baeticus, Teucrium capitatum, etc.. En altitudes de 800- $900 \mathrm{~m}$, hacia la parte oriental de la sierra, aparece frecuentemente un coscojar (Quercus coccifera) de porte achaparrado 
que supone el paso a condiciones semiáridas. Sobre substratos calizos o dolomíticos los matorrales están dominados por romerales con abundancia de plantas esenciales (Ulex parviflorus, Lavandula lanata, Rosmarinus officinalis, Cistus albidus, Sideritis foetens, Digitalis oscura, Phlomis purpurea, Brachypodium retusum, Santolina chamaecyparissus, Thymus baeticus, etc.. En las zonas degradadas sólo queda una vegetación serial formada por retamares, bolinares con aulagas (Ulex parviflorus), jarales, tomillares y espartales (Stipa tenacissima, Avenula bromoides, Arrhenaterun elatius, etc.. En las partes más bajas del piso mesomediterráneo $(600-900 \mathrm{~m})$, bien representadas en la parte oriental de la sierra, entre Ohanes y Alboloduy a los matorrales de retamas, aulagas y albaidas (Anthyllis cytisoides) se les unen lentiscos (Pistacia lentiscus) y acebuches (Olea europaea).

En amplias zonas de este piso de vegetación se han venido haciendo repoblaciones de pinos (Pinus sylvestris, Pinus nigra,en las zonas más altas, y Pinus halepensis en las partes más bajas ) que, actualmente, consolidan formaciones boscosas considerables. Del mismo modo, esta sierra se ha cultivado en las partes más favorables con sementaras de secano, almendros y viñas. Muchas parcelas están abandonadas y han sido colonizadas por tomillares nitrófilos con Santolina rosmarinifolia, Helichrysum stoechas, Artemisia campestris subsp. glutinosa, Artemisia barrelieri, Eryngium campestre, etc..

\subsection{La sierra de Gádor}

Limita por el sur y en su extremo oriental con la cuenca neógena del Andarax. Es una alta montaña cuyas laderas tienen pendientes, con frecuencia, superiores al $80 \%$ (sobre todo en los flancos de la sierra) y los desniveles relativos superan los $1.000 \mathrm{~m}$. Las alturas absolutas pueden rebasar los $2.200 \mathrm{~m}$ en el extremo occidental; mientras que en el oriental la altitud se rebaja hasta los $1.000 \mathrm{~m}$ y termina en los alrededores de la ciudad de Almería con sólo 700 $\mathrm{m}$ sobre el nivel del mar.

Está constituida por series litológicas pertenecientes a varios mantos de corrimiento de gran envergadura de las Zonas Internas de las Cordilleras Béticas plegados en un enorme anticlinorio. En definitiva, constituye un imponente edificio de dolomías y calizas alpujárrides pertenecientes al manto de Lújar (= Gádor) que significan el $85 \%$ de la sierra. Además, están implicados otros conjuntos de rocas, como sucede en el flanco norte de la sierra, al este de Alhama y en el extremo occidental, donde afloran retazos del zócalo del manto de Lújar (= Gádor) constituido por esquistos calcáreos y margas, así como importantes afloramientos del manto de Murtas (= Felix), constituidos por amplias zonas de filitas subyacentes a retazos de su cobertera dolomítica. Estas áreas de esquistos, margas y filitas vienen a suponer el $10 \%$ de la sierra. 
El predominio de dolomías, calizas y filitas (launas) le dan a la sierra una coloración oscura con matices que van desde el marrón al violáceo.

Aparte de la tectónica de "unidades desplazadas" (mantos de corrimiento), la sierra de Gádor está afectada por una importante red de fallas que, en líneas generales, pertenecen a distintos sistemas. Uno de dirección NO-SE que sigue, sensiblemente, la alineación de la sierra; cuyo flanco norte está afectado por otro sistema de fallas de dirección O-E que pone en contacto mecánico dicho flanco con las litologías neógenas de la cuenca del Andarax. Finalmente, un tercer sistema de fallas, menos desarrollado, de dirección NNE-SSO y, por lo tanto, transversal a los anteriores también afecta al edificio de la sierra. Esta red de fallas ha troceado la bóveda del anticlinorio y ha provocado un juego de bloques hundidos y levantados en el conjunto de la sierra, dando lugar a que en la zona central del edificio aparezcan frecuentes zonas relativamente planas (La Zarba, El Campillo de Huécija, La Chanata, Los Cantos de la Muela) en donde se conservan retazos de la sedimentación marina de la cuenca tortoniense en forma de calcarenitas conglomeráticas sobre las que, se han venido a acumular importantes depósitos de coluviones y aluviones cuaternarios (depósitos de ladera, pequeños abanicos aluviales) a favor de los débiles valores de la pendiente. En contrapartida, los bloques elevados constituyen pilares tectónicos que llegan a sobrepasar los $2.000 \mathrm{~m}$ de altitud, al tiempo que el sistema de fallas longitudinales es también responsable de que los flancos de la sierra sean tan escarpados. Este sistema de fallas es relativamente reciente, con funcionamiento subactual, y hay que relacionarlo con los fenómenos de termalismo existentes en las proximidades de Alhama de Almería. La actividad reciente de estas fallas ha inducido a la red fluvial a un intenso encajamiento que ha producido profundas gargantas en el último tramo de todos los barrancos importantes que salen de la sierra (Huéchar, Fuerte, Colomina, Alcora, etc.). En la sierra se pueden distinguir dos subunidades de paisaje diferentes:

La zona de cumbres es una de ellas, con una extensión de 13.258 Ha que suman el 13,4\% del total del área estudiada. Constituye la bóveda del anticlinorio y su altura aumenta sensiblemente desde la zona oriental hacia la occidental, llegándose a rebasar los $2.200 \mathrm{~m}$, aunque en notables extensiones la altitud se mantiene entre 1.400 y $1.800 \mathrm{~m}$, correspondiendo las mayores altitudes a los pilares tectónicos. Son frecuentes la morfologías domáticas (lomas de gran radio de curvatura) coincidentes con las charnelas de los anticlinales.

$\mathrm{Su}$ aspecto amesetado es evidente en amplias zonas como consecuencia del juego de bloques antes aludido que ha hundido gran parte de la bóveda del anticlinorio y explica la existencia de amplias áreas con pendientes comprendidas entre el 20 y el $40 \%$ (incluso en extensiones importantes las pendientes están alrededor del 8\%). Algunas de estas áreas amesetadas coinciden con 
afloramientos de litologías neógenas (calcarenitas) y con rellenos cuaternarios. Además, el nivel de cumbres permite señalar una superficie de erosión finimiocena desnivelada por el juego de las fallas señaladas anteriormente. La erosión fluvial está representada por las cabeceras y el curso medio de los barrancos, cuyo encajamiento ha sido de moderado a fuerte.

La vegetación de la sierra de Gádor también responde a la gradación climática que introduce la altitud, pudiéndose distinguir comunidades vegetales diferentes desde las cumbres hasta las zonas basales. Por encima de los 2.100 m está el piso oromediterráneo, que se alcanza en la parte suroccidental, cuya vegetación potencial es un pinar claro, bajo el que se instalaría un sabinal mezclado con enebros; pero la acción antrópica lo ha degradado y en su lugar, actualmente, lo que hay son espinales arbustivos con rosales y espinos (Rosa sicula, Berberis hispanica, Lonicera arborea, Crataegus brevispina, Ononis aragonensis, Prunus ramburii, Rhamnus saxatilis, etc); aunque la etapa subserial más extendida es un matorral de especies espinosas con Erinacea anthillis, Vella spinosa, Alyssum spinosum, Buplerum spinosum, entre otras, que presentan una fisonomía característica de tipo almohadillado, así como lastonares (Avenulo bromoides-Helictotrichetum cazorlensis) y pastizales con gramíneas y leguminosas (Festuca hystrix, Poa ligulata, Astragalus tremolsianus, Astragalus nummularoides, etc.).

Entre los 1.600 y los $2.100 \mathrm{~m}$ de altura está el piso supramediterráneo cuya vegetación potencial es un bosque de encinas (Quercus rotundifolia) poco denso; pero lo que existe actualmente es una vegetación serial formada por arbustos espinosos (Crataegus monogyna, Berberis hispanica, Rosa pouzinii, etc.), lastonares y matorrales almohadillados semejantes a los descritos en el piso anterior.

Más abajo, entre 750 y 1.700 m, está el piso mesomediterráneo cuya vegetación potencial es, también, un encinar de Quercus rotundifolia, del que sólo quedan restos aislados. En su lugar hay monte alto con coscojas (Quercus coccífera), matorrales con lavandas, aulagas, bolinas, romeros, jaras, retamas y lastonares. En la parte occidental de la sierra, sobre roquedo de filitas, se desarrolla un extenso retamar compuesto casi exclusivamente por Adenocarpus decorticans que se enriquece con Genista cinerea sobre materiales carbonatados.

En amplias zonas de la sierra existen repoblaciones de pinos a base de Pinus pinaster y Pinus nigra con alto grado de cobertura, en el piso supramediterráneo, mientras que en el piso mesomediterráneo se ha repoblado con pino carrasco (Pinus halepensis) . Además, el territorio serrano ha tenido un uso del suelo predominantemente forestal, aunque la relativa debilidad de las pendientes ha permitido los cultivos con sementeras y almendrales de secano en algunas zonas. 
La ladera de la sierra, en su flanco norte, es otra subunidad de paisaje que se perfila de manera brusca sobre la cuenca neógena del Andarax. Se le ha calculado una superficie de $16.302 \mathrm{Ha}$ que supone el 16,5\% del total del valle del Andarax. Sus laderas son muy escarpadas, con pendientes que superan el $80 \%$. Además, están profundamente recortadas por barrancos, cuyos perfiles longitudinales experimentan bruscas rupturas de pendiente y cuyos cauces han de salvar fuertes desniveles en muy corto trecho, encajados en angostas gargantas. También, en los afloramientos de filitas y esquistos se pueden reconocer frecuentes despegues y deslizamientos de ladera con morfologías caóticas que ponen en evidencia la actividad sísmica de la zona.

La ladera norte de la sierra Gádor participa de la vegetación del piso mesomediterráneo en las partes más altas y del piso termomediterráneo en la parte baja. En el piso mesomediterráneo se pueden encontrar pequeños bosquetes de encinares calcícolas (Quercus rotundifolia) en la parte occidental; pero el aspecto general de esta ladera es un monte alto, bien desarrollado, en general, con coscojares, espinos negros (Rhamnus eleodes) y enebros, junto con un matorral denso de aulagas, romeros y jaras. En las zonas más cercanas al piedemonte el piso termomediterráneo está representado por un matorral de lentiscos (Pistacia lentiscus) y retamares con Genista retamoides, Asparagus horridus y Asparragus albus, salpicado de acebuches (Olea europea). Esta unidad de paisaje, debido a la fuerte pendiente de las laderas, no sólo no se ha utilizado para cultivos sino que ha sido objeto de medidas de protección para evitar la acción de las aguas de arroyada, de tal modo que en amplias zonas las laderas están repobladas con Pinus halepensis (pino carrasco), constituyendo pinares densos y bien conservados desde Alhama de Almería hasta Canjáyar.

\subsection{La sierra de Alhamilla}

Sólo su extremo occidental pertenece a la cuenca hidrográfica del río Andarax, con una extensión de 3.440 Ha que significan el 3,5 \% de dicha cuenca. Es una alineación montañosa con dirección O-E que en la zona de cumbres llega a alcanzar casi los $1.400 \mathrm{~m}$ (1.365 m sierra Alhamilla, $1.387 \mathrm{~m}$ Colativí), rebajándose la altitud hacia los extremos occidental y oriental. Se puede considerar como una montaña alta en la que los desniveles relativos con el entorno alcanzan los $1.000 \mathrm{~m}$ y las laderas presentan pendientes que oscilan entre 55 y $80 \%$.

Está constituida, fundamentalmente, por el apilamiento de mantos de dos de los complejos tectónicos que forman las Unidades Internas de las Cordilleras Béticas: el complejo Nevado-Filábride y el complejo Alpujárride. El núcleo de la sierra está formado por micasquistos del complejo Nevado-Filábride deformados en una gran bóveda asimilable a un gran anticlinal; mientras 
que el flanco sur está constituido por los materiales replegados del complejo Alpujárride que cabalgan a los micasquistos nevado-filábrides. El complejo Alpujárride está constituido en esta zona por un zócalo de micasquistos y filitas y por una cobertera de calizas dolomíticas. El frente de cabalgamiento de estos materiales sobre los que constituyen el núcleo de la sierra es muy nítido en todo el flanco sur, sobre todo en los extensos afloramientos dolomíticos que contrastan fuertemente con los micasquistos subyacentes.

Una red de fallas de dirección NO-SE afecta a todo este flanco sur y se prolongan en la cuenca neógena; de manera que el contacto con los materiales de dicha cuenca es, casi siempre, de tipo mecánico. Dichas fallas mantienen su actividad en la actualidad, que se complementa con manifestaciones termales (Baños de sierra de Alhamilla). Las coloraciones de las rocas que constituyen esta sierra, que van desde los ocres oscuros hasta los violáceos, contrastan bien con la gama de colores más clara de la cuenca neógena y de los piedemontes.

El modelado de sierra Alhamilla presenta varios matices. En la zona central, constituida por micasquistos, la incisión moderada de la red fluvial y la superficie de erosión finimiocena que afecta a las cumbres, configuran un paisaje de interfluvios alomados de los que sólo sobresalen algunos picachos como consecuencia de afloramientos cuarcíticos. Sin embargo el flanco está bastante más accidentado, puesto que el contraste litológico entre las dolomías alpujárrides de la cobertera y las filitas y los micasquistos del zócalo ha sido explotado por la escorrentía fluvial de tal manera que extensos afloramientos del zócalo han sido exhumados por la erosión lineal profundizando grandes barranqueras. Además, en algunas zonas, grandes paquetes de la cobertera dolomítica han despegado de la base filítica provocando deslizamientos que, si no son de largo recorrido, afectan a amplias zonas de laderas, manifestándose con morfologías caóticas en las dolomías desplazadas, como ocurre en la zona de los Baños de sierra Alhamilla. A ello se le suman los procesos disolutivos generalizados, subaéreos y subterráneos, de dichas dolomías, que han dejado relieves residuales llamativos. Las condiciones tectónicas y la conjunción de procesos erosivos en un modelado diferencial han configurado en el flanco sur de la sierra un paisaje abrupto en el que se alternan picachos dolomíticos residuales, gargantas fluviales, barranqueras labradas en las filitas, escarpes de falla y frentes de cabalgamiento.

En lo que se refiere a la vegetación, en la sierra de Alhamilla, debido a su menor altitud, no existe el piso oromediterráneo. Desde los $800 \mathrm{~m}$ hasta la cumbre pertenece al piso supramediterráneo inferior y al piso mesomediterráneo, cuya vegetación está representada actualmente por un encinar (Quercus rotundifolia) bien conservado, aunque poco denso, entre los 850 y $1.000 \mathrm{~m}$, y por un matorral de jaras (Cistus albidus, Cistus ladanifer)), aulagas (Ulex 
parviflorus), cantuesos (Lavandula stoechas), bolinas (Genista umbellata) y retamas (Retama sphaerocarpa). En las zonas más degradadas sólo quedan retamares, lastonares, jarales (a veces en extensas superficies con cobertura monoespecífica de Cistus albidus) y espartales (Stipa tenacissima), a los que se les unen los palmitos (Chamaerops humilis) y las esparragueras (Asparragus horridus, Asparragus albus) en las zonas más térmicas. Más abajo, entre 400 y $800 \mathrm{~m}$, lo que existe es un matorral del piso termomediterráneo formado por espartales y tomillares en donde domina el esparto (Stipa tenacissima), acompañado de boleas (Thymelaea hirsuta), salsolas (Atriplici-Salsoletum genistoides) y bojas (Artemisia barrelieri).

En esta parte de la sierra hay pocas evidencias de cultivos, habiéndose dedicado el territorio a usos mineros, forestales y ganaderos.

\subsection{Los piedemontes}

Los piedemontes son otra unidad de paisaje fácilmente perceptible por el cambio brusco del valor de las pendientes, por la distinta litología y por las morfologías menos abruptas, por la coloración de las rocas (distintas tonalidades de ocres y de grises), por la cubierta vegetal y por el uso del suelo. Se le ha calculado una superficie de 9.897 Ha que suman el $10 \%$ del total del área de estudio.

Las pendientes oscilan entre el 12 y el $20 \%$ y los desniveles relativos se encuentran entre 50 y $200 \mathrm{~m}$. Por lo tanto son paisajes con topografías moderadamente escarpadas con colinas numerosas constituidas por restos de importantes acumulaciones escalonadas que han sido acarreadas por los elementos fluviales que bajan de las sierras. Son retazos de conos de deyección y de glacis-conos que debieron adaptar su nivel de acumulación a los sucesivos cambios de su nivel de base, que ha correspondido siempre al nivel de profundización de la red fluvial del río Andarax instalada en la cuenca neógena. Aunque con bastantes analogías, existen diferencias entre los piedemontes de Sierra Nevada, el de sierra de Gádor y el de sierra de Alhamilla.

El piedemonte del flanco sur de Sierra Nevada, es el menos extenso. Sólo se reconoce en la cabecera del Andarax donde los abanicos aluviales de los torrentes que inician la cabecera del río junto con los que bajan de la sierra de Gádor han rellenado una pequeña cuenca intramontañosa (fosa tectónica) en los alrededores de Laujar y Fondón. Es un área de topografía ondulada con pendientes inferiores al 12\% y desniveles relativos de 10-50 m, debido al poco encajamiento de la red fluvial. Sin embargo, entre Beires y Ohanes, los barrancos que bajan de la sierra de Beires han construido amplios abanicos aluviales actualmente destrozados por la erosión de los propios barrancos y reducidos a plataformas alargadas sobre las que se asientan los pueblos de Al- 
mócita y Padules. Aquí la topografía es más escarpada con colinas numerosas separadas por torrenteras cuyas laderas tienen pendientes que oscilan entre el 12 y el $20 \%$.

La vegetación potencial de este piedemonte corresponde al piso mesomediterráneo inferior y estaría representada por encinares (Quercus rotundifolia), de los que quedan restos adehesados dominados por romerales, mezclados con bolinares y espartales. Las zonas con suelos más potentes soportan un retamar con Retama sphaerocarpa y Genista cinerea.

Por otro lado, la pequeña cuenca de Laujar-Fondón, tradicionalmente, ha tenido un uso agrícola con cultivos mixtos de sementeras de secano y de regadío, con olivos, almendros y frutales. El piedemonte entre Beires y Ohanes, aparte del olivar, ha sido la cuna del cultivo de los parrales de uva de mesa que han durado hasta las últimas décadas del siglo XX. El declive de los parrales ha provocado el abandono de múltiples parcelas de cultivo en forma de bancales, con el consiguiente peligro de aceleración de la erosión.

El piedemonte de la sierra de Gádor es el más extenso y se puede reconocer, aunque con soluciones de continuidad, desde el extremo occidental de la cuenca hasta la ciudad de Almería. Las cubiertas de los glacis-conos que lo configuran han sido acarreadas por los numerosos barrancos que bajan de la sierra de Gádor y recubren parte de la sedimentación neógena del valle del Andarax. La red de fallas que accidentan el flanco de la sierra ponen en contacto brusco la enorme masa calizo-dolomítica de la montaña (cuyas características estructurales le permite ser una importante reserva hidrogeológica) con las litologías de la cuenca neógena. En dicho contacto han aflorado numerosos manantiales cuya intensidad ha variado en función de los cambios climáticos de los últimos dos millones de años (pluviales e interpluviales cuaternarios). De su actividad en períodos pluviales quedan manifestaciones de acumulaciones en forma de restos de lo que debieron ser importantes mantos de travertinos. Además, los niveles de glacis-conos más antiguos presentan importantes encostramientos tanto en la superficie como en la base de la cubierta.

El piedemonte de la sierra de Gádor está constituido por tres niveles de glacis-conos cuyos ápices arrancan de los barrancos a su salida del flanco de la sierra. El nivel más antiguo (Cuaternario antiguo) está bien desarrollado en la ladera norte de la sierra desde la cabecera de la cuenca hasta Benhadux; y en el extremo oriental, al norte de la ciudad de Almería (zona del Cementerio y Torrecárdenas). Su cubierta conglomerática está fuertemente encostrada en amplias extensiones. Las incisiones de la red de ramblas y barrancos han elaborado escarpes de algunas decenas de metros entre la cubierta de este glacis y las del Cuaternario medio. Dicho escarpe evoluciona por desprendimientos causados por los socavones y acarcavamientos producidos por la escorrentía hídrica superficial en las margas y arenas pliocenas subyacentes. Los niveles 
de glacis del Pleistoceno medio y superior no presentan el mismo grado de encostramiento en sus cubiertas aunque, en algunas zonas aparezcan afloramientos de costras pedogenéticas que representan un horizonte petrocálcico exhumado. Todo el piedemonte está afectado por la neotectónica cuaternaria, incluso los niveles del Cuaternario medio. Se pueden distinguir dos subunidades de paisaje en el piedemonte:

Las cubiertas de los glacis-conos y de los conos de deyección, formados por acumulaciones detríticas, con frecuencia encostrados o recubiertas por importantes bancos de travertinos. Son las coronas de las numerosas colinas anteriormente citadas, en las que predominan colores rojizos y ocres y que, en general, están poco cultivadas.

Los valles y vaguadas que se intercalan entre estas cubiertas de acarreos torrenciales, modelados por el encajamiento de la red fluvial desde el Cuaternario medio, junto con algunos niveles de aplanamiento más recientes, cuya litología es diferente ya que, además de las coberteras detríticas poco encostradas, son frecuentes los afloramientos de rocas margosas, grises y amarillentas, pertenecientes al relleno neógeno de la cuenca que, por otra parte, son siempre el soporte de todas las cubiertas detríticas antes mencionadas.

Esta subunidad de paisaje está sometida a procesos crónicos de erosión en cierto modo diferentes de la anterior, tales como la formación de barranqueras que explotan la fragilidad de las cubiertas detríticas no encostradas y los niveles de margas arcillosas subyacentes; así como los movimientos en masa de laderas (desprendimientos de la cubierta superior, deslizamientos, solifluxión, etc.) facilitados por la propensión de las margas arcillosas a deslizarse en presencia de agua (manantiales o precipitaciones abundantes) siempre que se sobrepase la pendiente límite o de despegue y, además, la formación de pequeñas galerías o sifones (piping), conocidas como ratoneros, en los terrenos margo-arcillosos (gredas).

El piedemonte de la sierra de Gádor participa de dos pisos de vegetación. En la parte occidental, más arriba de Canjáyar, pertenece al piso mesomediterráneo inferior y su vegetación potencial es un encinar de Quercus rotundifolia del que quedan individuos aislados y un monte alto de chaparros y espinos que, en las áreas mas degradadas, es un matorral de aulagas, bolinas, romeros y retamas. La parte centro-oriental, desde Canjáyar hacia abajo, pertenece al piso termomediterráneo, cuya vegetación actual es un matorral discontinuo formado por lentiscos, aulagas, esparragueras, alcaparreras (Capparis spino$s a$ ), salsolas, espartos y tomillos.

A pesar de su dinámica geomorfológica, esta unidad de paisaje está ocupada en gran parte por cultivos de regadío que han necesitado un previo acondicionamiento en bancales. Durante casi cien años, desde finales del siglo XIX hasta las últimas décadas del siglo XX, el cultivo fundamental ha sido el de 
los parrales para uva de mesa con orientación hacia la exportación. El cambio de coyuntura económica para la uva motivó el abandono de este cultivo y el abandono de numerosos bancales. En el último lustro, los olivares, viñedos e, incluso, invernaderos están ocupando este espacio.

En el piedemonte de sierra Alhamilla el sustrato está constituido por margas mio-pliocenas, con intercalaciones de yesos en algunas zonas. La serie termina en un conglomerado con bolas de cuarzo en su interior y fuertemente endurecido que se asimila al nivel de playa en el tránsito Plioceno-Pleistoceno. Los barrancos y ramblas que bajan del flanco sur de la sierra de Alhamilla han configurado un modelado de glacis-conos y de abanicos aluviales que imprimen carácter a este piedemonte. El nivel de glacis más extenso es el que corresponde al Cuaternario antiguo, cuyos ápices se apoyan en la sierra y las zonas distales llegan hasta las cercanías del litoral actual. Este nivel de glacis fosiliza con su cubierta detrítica amplias zonas del conglomerado marino pliocuaternario; pero en otros sitios lo bisela. De todos modos la superficie de este glacis se presenta, en general, fuertemente encostrada. Además, el progresivo levantamiento de la sierra y la regresión marina cuaternaria ha mantenido el poder erosivo de las ramblas, que han destrozado gran parte del glacis, sobre todo en las cercanías de la sierra, dejando al descubierto las margas pliocenas. Sobre ellas se ha desarrollado un modelado de cárcavas similar al del valle del Andarax, a la vez que la cubierta del glacis junto con el conglomerado marino plio-cuaternario han retrocedido como consecuencia de espectaculares desprendimientos. Así que, actualmente, quedan unas morfologías con los restos de cubiertas del glacis colgados, con despeñaderos en los bordes, cárcavas generalizadas en las margas y una red de ramblas de fondo plano tapizado de arenales. Los ejemplos más llamativos de este paisaje están en la rambla de San Indalecio, cerca de los Baños de sierra Alhamilla.

Los niveles del Cuaternario medio y superior son glacis-conos o abanicos aluviales encajados en el nivel de glacis más viejo. Los más desarrollados están en la rambla de San Indalecio y en los alrededores del Campamento de Viator. Sus cubiertas no están cementadas y están constituidas por acarreos de gravas, arenas y limos. Todo el piedemonte está afectado por la neotectónica cuaternaria, que se traduce en una densa red de fallas en sentido NO-SE, pertenecientes a las llamadas fallas del Alquián.

Como consecuencia de estas formas de modelado se pueden distinguir en el piedemonte de sierra Alhamilla dos subunidades de paisaje diferentes. Una coincide con la zona más cercana a la sierra, con cubiertas de glacis destrozadas, cárcavas y abarrancamientos, que se puede considerar como una topografía moderadamente escarpada con numerosas colinas con desniveles relativos de 50-200 m y cuyas pendientes oscilan entre el 12 y el $20 \%$. Otro paisaje se desarrolla sobre la zona distal de los glacis y abanicos aluviales, en 
donde predomina la acumulación frente al encajamiento, configurándose una topografía ondulada con pendientes inferiores al $12 \%$ y desniveles relativos de $10-50 \mathrm{~m}$.

Este piedemonte pertenece al piso de vegetación termomediterráneo, cuyas comunidades actuales forman un matorral de retamas, romeros, boleas, esparragueras, alcaparreras, soseras (salsolas), espartos, bojas y tomillos. El territorio no ha estado muy cultivado, a no ser en algunos abanicos aluviales recientes con cultivos de secano, hoy abandonados. Sin embargo, en los últimos años empiezan a ganar espacio, con fuerza, los invernaderos.

\subsection{El sistema de cárcavas de la cuenca neógena}

La cuenca neógena del Andarax es un sinclinal que se continúa hacia el este por la cuenca de Sorbas para terminar en la cuenca neógena de Vera en el levante de la provincia de Almería, junto al mar Mediterráneo. Se originó en una etapa distensiva post-orogénica y separa la sierra de Gádor, al sur, de la Sierra Nevada al noroeste y de la sierra de los Filabres al norte. Tiene una extensión de 21.203 Ha que significan el 21,4\% del total del área estudiada.

El relleno marino de la cuenca comienza por una sedimentación de borde de cuenca que presenta distintas facies. En la cabecera de la cuenca y a lo largo de todo el flanco sur de Sierra Nevada, dicha sedimentación está constituida por conglomerados con grandes bloques englobados en una matriz arcillosa de color rojizo; mientras que entre Alhama y Gádor y en los alrededores de Almería afloran calcarenitas y margas arenosas. Sigue con una facies de cuenca profunda, formada por potentes series de margas con algunas intercalaciones de arenas y yesos, que aflora entre Canjáyar y Alhama, coincidiendo con el eje de la cuenca, y finaliza con una serie regresiva constituida por margas arenosas y conglomerados y que se localiza un poco más al norte desde Padules hasta Alhabia. Desde la confluencia del río Nacimiento hasta Santa Fe de Mondújar, la zona central de la cuenca está ocupada por afloramientos de margas y conglomerados continentales pliocenos y desde Santa Fe de Mondújar comienza un cuerpo deltaico que se extiende hasta las cercanías de la desembocadura del río Andarax. Todas estas litologías tienen una paleta de colores en la que dominan los grises, amarillentos y ocres, lo que confiere al conjunto de la cuenca neógena una coloración más clara que contrasta con las irisaciones oscuras de la sierras de alrededor.

La red fluvial ha explotado con relativa facilidad estas litologías poco resistentes a la erosión lineal y ha modelado un extenso paisaje de cárcavas que dejan entre sí numerosas colinas alargadas, a la manera de espigones. Sus laderas tienen pendientes comprendidas entre el 12 y el $20 \%$ y desniveles relativos que oscilan entre 50 y $200 \mathrm{~m}$., resultando una topografía modera- 
damente escarpada. El abarrancamiento, producido con un patrón de drenaje dendrítico, es el rasgo común de este sistema de paisaje. Pero las distintas litologías introducen matices en dicho patrón de drenaje y permiten distinguir varias unidades:

a) Sobre las litologías más conglomeráticas el patrón de drenaje es menos denso y los interfluvios presentan con frecuencia lomas convexas.

b) Sobre las margas con arenas y yesos de la facies profunda el patrón de drenaje es más denso, los interfluvios tienen cumbres más estrechas. Sobre estas rocas las laderas se agrietan con facilidad en la estación seca o se producen repetidos deslizamientos durante la estación húmeda. También es frecuente que aparezcan eflorescencias salinas en superficie, producidas evaporación del agua que asciende en los suelos por capilaridad, así como frecuentes fenómenos de piping (formación de galerías y sifones) a consecuencia de la disolución de yesos interestratificados en estas formaciones detríticas.

c) Finalmente, sobre las margas, arenas, y limos del cuerpo deltaico el patrón de drenaje se hace extremadamente denso y los interfluvios muy estrechos y poco resistentes. En este caso la erosión por escorrentía superficial alcanza los valores máximos.

En el borde de la cuenca en contacto con el extremo oriental de la sierra de Gádor, así como en la margen que fosiliza el extremo occidental de la sierra de Alhamilla existen formas de relieve diferentes a las del resto de la cuenca. En el primer ámbito, los restos de calcarenitas del borde de la antigua cuenca marina fosilizan el flanco de la sierra, en todo su frente oriental y un poco en la ladera norte, hasta alturas de $300 \mathrm{~m}$. En dicho frente oriental quedan restos de una superficie de erosión marina plio-cuaternaria colgada a 80-100 m sobre los acantilados de la costa entre Almería y Aguadulce. Un poco más hacia el norte, la erosión fluvial ha dejado pequeñas plataformas residuales en forma de pequeñas cuestas con el frente hacia la sierra, como sucede al norte de la ciudad de Almería; mientras que otras veces son pequeños cerros testigos. Sólo alcanzan la categoría de relieve tabular sobre las calcarenitas y calizas arrecifales messiniense-andalucienses del flanco norte (alrededores del Cortijo de Araoz), actualmente explotadas por una cercana fábrica de cemento. Por debajo de este nivel de pequeños relieves residuales se desarrolla el piedemonte que fosiliza el relleno arenoso-limoso de un cuerpo deltaico que ocupó toda esta zona de la cuenca desde el Plioceno.

En el borde de la cuenca que limita con sierra Alhamilla, hasta la altura de rambla Quemada, el esquema es similar. En el extremo oriental de la sierra, las intercalaciones de areniscas en las margas turbidíticas producen las condi- 
ciones para que los barrancos hayan modelado un relieve monoclinal (Cerro de Alfaro, $742 \mathrm{~m}$.), con el frente hacia la sierra, que ha sido desnivelado, aún más, por el levantamiento del macizo montañoso a causa de la neotectónica cuaternaria que, a la vez, ha trastocado todos los niveles de glacis, tanto los del piedemonte de la sierra de Gádor como los de la sierra de Alhamilla.

La vegetación natural de la cuenca neógena pertenece al piso mesomediterráneo inferior, más arriba de Canjáyar, y se presenta formando un matorral con aulagas, bolinas, romeros, espartos y tomillos. La parte media y baja de la cuenca pertenece al piso termomediterráneo cuya vegetación potencial correspondería a formaciones arbustivas discontinuas pertenecientes al azufaifal (Ziziphetum loti) del que actualmente no existe, prácticamente, representación. En su lugar, el paisaje está dominado por un tomillar abierto (Anabasio hispanicae-Euzomodendretum bourgeani), con poco grado de cobertura y muy alterado por el uso ganadero, alternando con espartales (Lapiedro martineziiStipetum tenacissimae) y albardinales (Dactylo-Lygeetum sparti). En los suelos más removidos y nitrogenados son frecuentes comunidades constituidas por Haloxylon tamariscifolium, Atriples glauca, Artemisia barrelieri, Salsola genistoides, Salsola vermiculata, etc.. Estas formaciones representan la facies más seca de este piso de vegetación.

El uso de este territorio por el hombre ha sido más ganadero que agrícola, ya que la naturaleza estructural de estas rocas (poca permeabilidad, débil cohesión) las hace muy poco resistentes frente a la erosión hídrica superficial (laminar, en surcos o en cárcavas), al tiempo que por su contenido en arcilla y yesos son propensas a facilitar deslizamientos de tierras. La aridez de la región se une para limitar el uso agrícola sólo a aquellas zonas concretas a las que, mediante encauzamiento, ha podido llevarse agua para riego. En algunas zonas existen repoblaciones con pino carrasco (Pinus halepensis) y aún quedan restos de la repoblación con chumberas (Opuntia ficus indica) llevada a cabo entre los años 1950 y 1960, en algunas áreas del centro de la cuenca.

\subsection{Las terrazas fluviales del río Andarax}

Se localizan en una franja cercana al cauce principal del río Andarax y de sus principales tributarios como son el río Nacimiento, la rambla de Gérgal y la rambla de Tabernas, habiéndoseles calculado una extensión de $7.391 \mathrm{Ha}$ que significan el 7,5\% del total del área de estudio. A lo largo del río Andarax existen cuatro niveles de terrazas. El nivel I está bien representado en la parte media del valle, en los alrededores de Íllar y, aguas abajo, entre el yacimiento prehistórico de los Millares (Santa Fé de Mondújar) hasta Pechina, a uno y a otro lado del río, así como, cerca de la desembocadura, entre Huércal y el Puche, al noreste de la ciudad de Almería. Es un nivel formado por una cubierta 
de varios metros de conglomerados de distinto grado de consolidación que enrasa, por arriba, con la zona distal del primer nivel de glacis. Los niveles II y III están menos representados y están formados por arenas y gravas medianamente consolidadas. El nivel IV es el más reciente y constituye el lecho de inundación episódico del río Andarax y de las ramblas tributarias. Arenas y limos constituyen su cubierta, cuyo grosor ha aumentado artificialmente en tiempos históricos como consecuencia de la derivación de aguas de avenida de los cauces principales mediante boqueras, de manera que este nivel, en algunos tramos, se replica en dos o tres subniveles casi continuos a lo largo de los cauces principales de la red fluvial.

El cauce del río Andarax así como los de sus afluentes van acompañados por vegetación de ribera, en parte natural y, en otra, plantada por el hombre, constituida por choperas (Populus alba), olmedas (Ulmus minor), saucedas (Salix atrocinerea), tarajales (Tamarix canariensis, Tamarix africana), cañas (Arundo donax) y carrizales en las orillas; mientras que en el interior de los cauces (sobre todo en los de los barrancos y las ramblas) aparecen adelfas (Nerium oleander), tarays, olivardas (Inula viscosa) y juncales (Cirsio-Holoschoenetum).

Todos los niveles de terrazas fluviales han sido usados tradicionalmente para cultivos, los cuales durante el siglo XX, se han sucedido desde los parrales, en la primera mitad, hasta los cítricos en la segunda. En los comienzos del siglo XXI , en la parte baja del valle están presionando con fuerza los invernaderos $y$, en el área de influencia de la ciudad de Almería, las urbanizaciones.

\subsection{El delta del río Andarax}

En el último tramo, al este de la ciudad de Almería, el río Andarax se abre en una amplia llanura aluvial a la que convergen otras más pequeñas originadas por abanicos aluviales de barrancos que bajan del extremo oriental de la sierra de Gádor y de la ladera meridional de sierra Alhamilla. Dicha llanura aluvial (de 1.883 Ha que significan el 1,9\% del total del territorio estudiado), construida sobre todo por los aportes del río, se ha ido configurando sobre un delta en ápice colmatado en tiempos históricos. Restos de cordones litorales y de pequeñas zonas de marismas, rellenadas recientemente por aportes torrenciales y eólicos, se encuentran entre el ápice del delta actual y la urbanización de Costacabana, al este de La Cañada de San Urbano. La llanura de acumulación del delta se traduce en una topografía suave con pendientes inferiores al $12 \%$ y con desniveles relativos que no alcanzan los $10 \mathrm{~m}$.

La vegetación potencial de este ámbito corresponde a un azufaifal ( $\mathrm{Zi}$ zifhetum loti), constituido por formaciones espinosas arbustivas dominadas por azufaifos (Zizipfus lotus), acompañadas de Withania frutescens, Salsola 
opossitifolia, Salsola genistoides, Artemisia barrelieri, etc.. Pero desde hace muchos siglos este territorio ha estado cultivado, constituyendo la vega de aprovisionamiento de la ciudad de Almería. Durante la segunda mitad del siglo XX se desarrollaron los cultivos enarenados, primero, y bajo invernadero, después; cuyo paisaje está retrocediendo rápidamente en los últimos años frente a la expansión urbana de Almería.

\section{CONCLUSIONES}

Según la metodología utilizada en trabajos anteriores (Ferre y Senciales, 1994 a y b; Díaz Garretas et al., 1996; Ferre, 1997 a y b) se han evaluado las condiciones ambientales de las unidades de paisaje del Valle del Andarax y los resultados se exponen en el cuadro $\mathrm{n}^{\circ} 2$. 


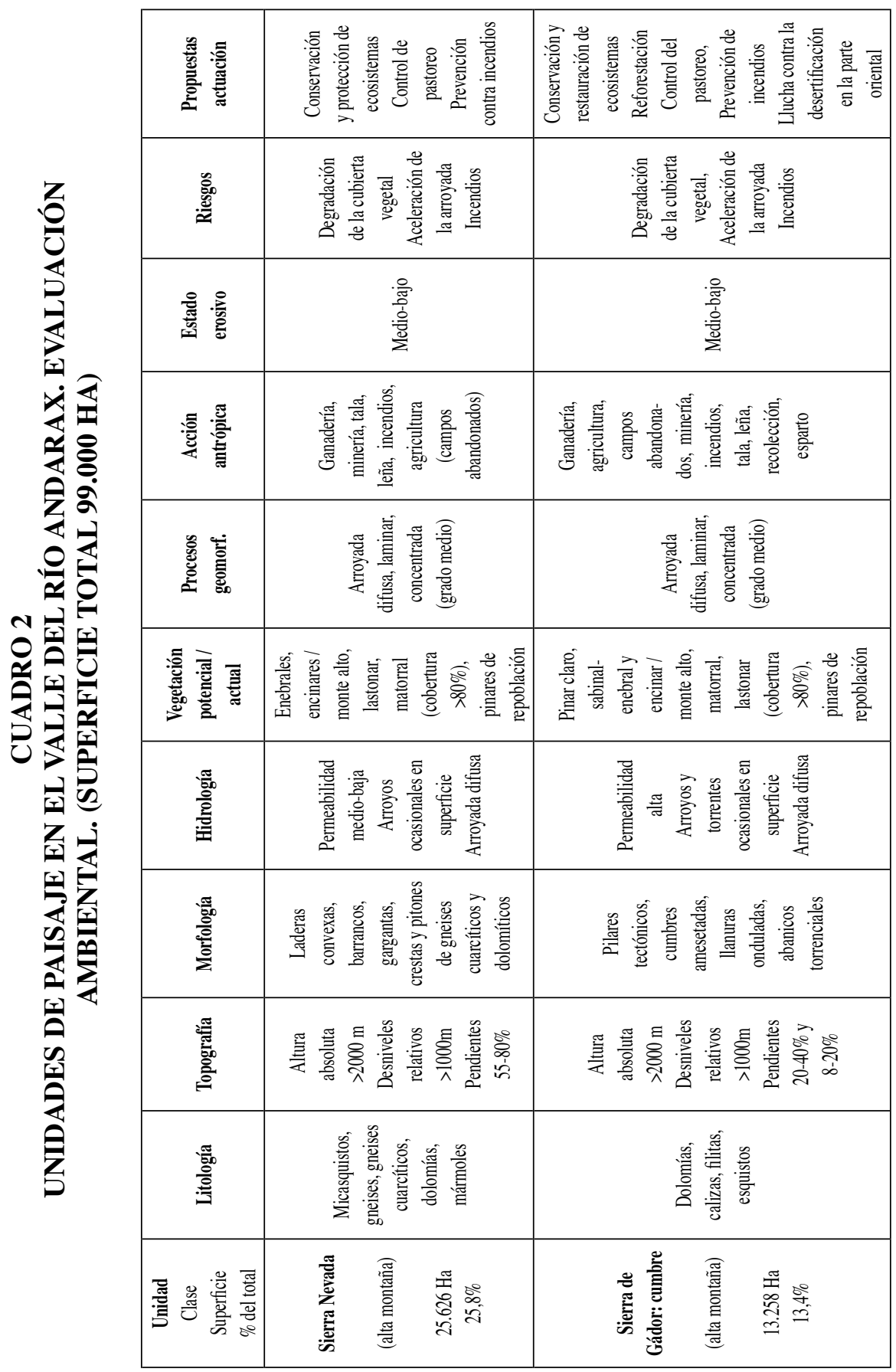




\begin{tabular}{|c|c|c|}
\hline 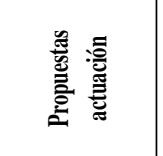 & 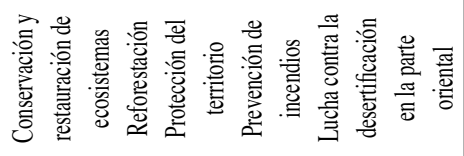 & 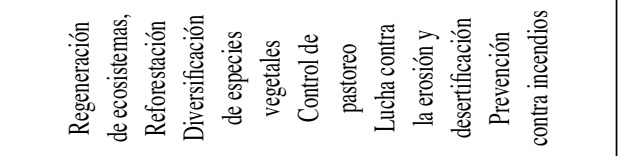 \\
\hline 䒿 & 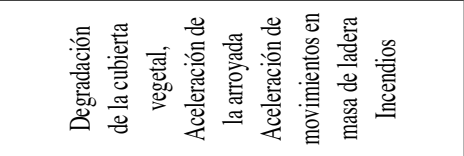 & 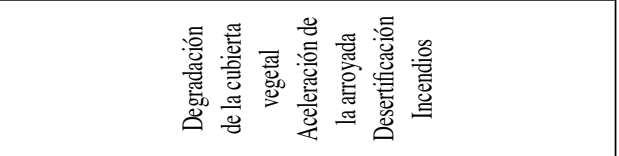 \\
\hline 咅高 & 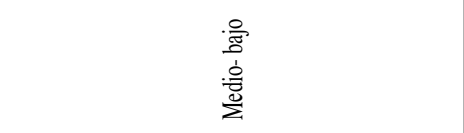 & $\begin{array}{l}\text { 율 } \\
\text { 总 } \\
\text { 哀 }\end{array}$ \\
\hline 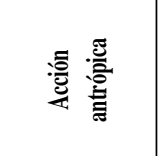 & 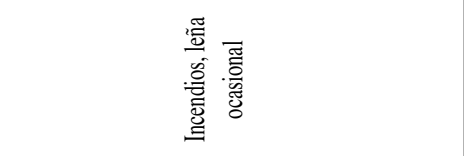 & 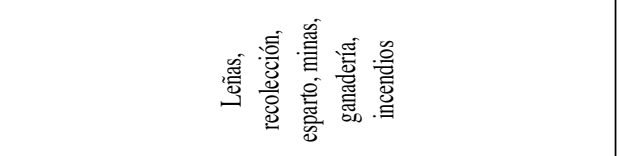 \\
\hline 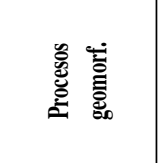 & 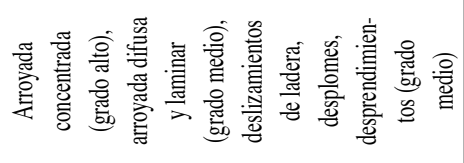 & 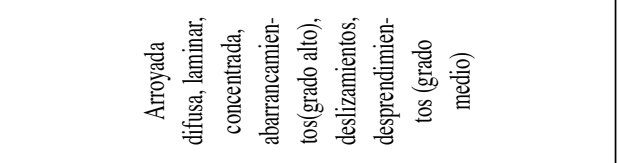 \\
\hline 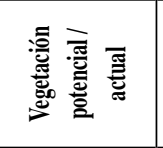 & 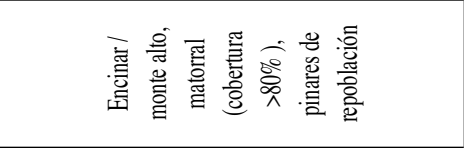 & 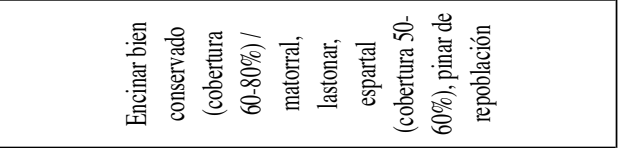 \\
\hline 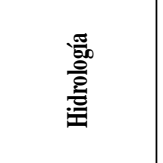 & 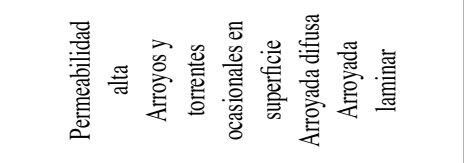 & 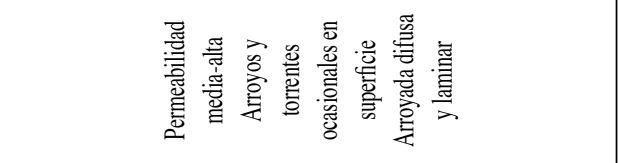 \\
\hline 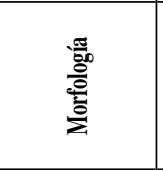 & 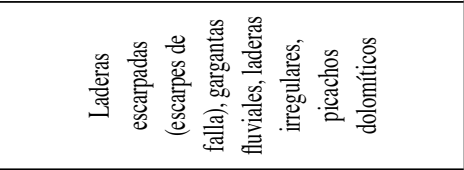 & 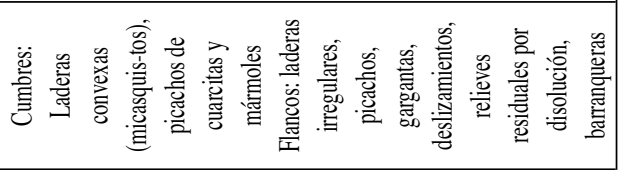 \\
\hline 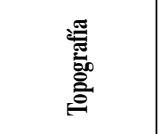 & 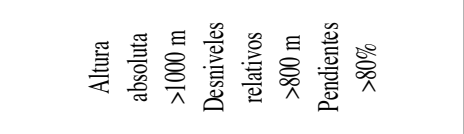 & 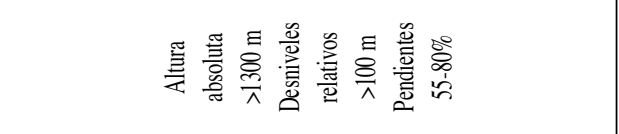 \\
\hline 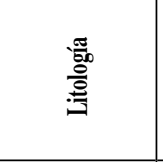 & 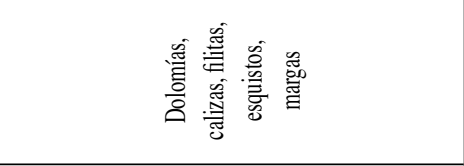 & 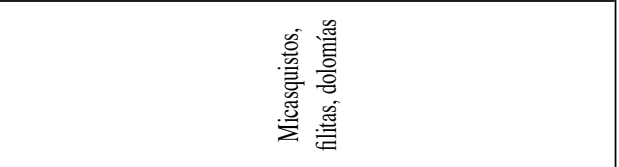 \\
\hline 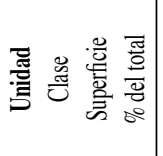 & 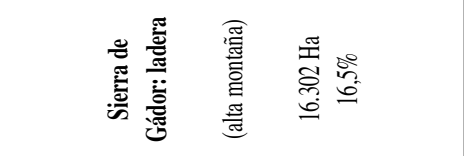 & 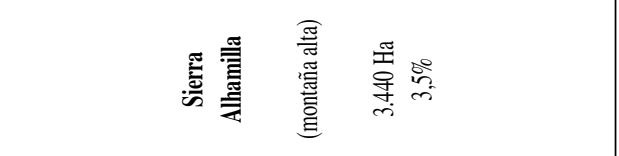 \\
\hline
\end{tabular}




\begin{tabular}{|c|c|}
\hline 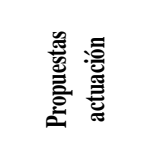 & 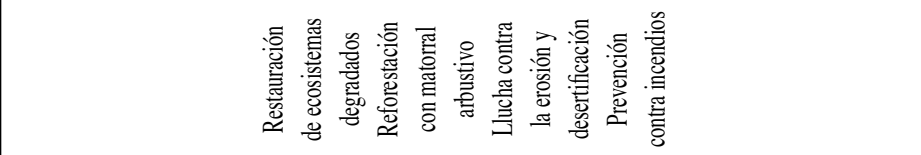 \\
\hline 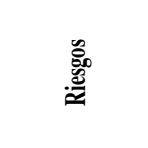 & 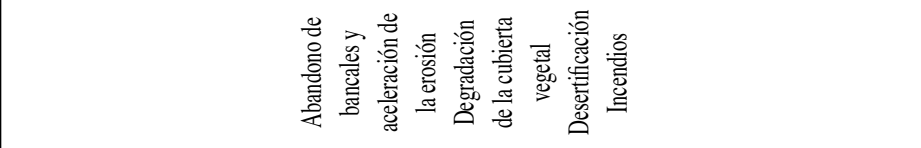 \\
\hline 咅高 & 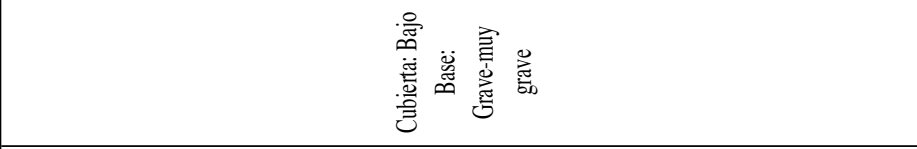 \\
\hline 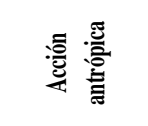 & 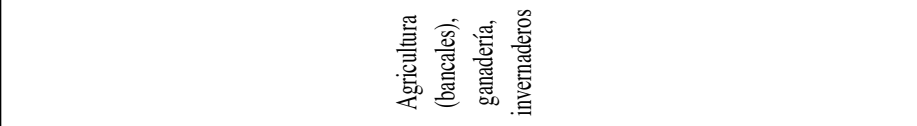 \\
\hline 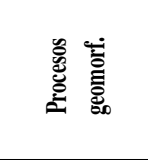 & 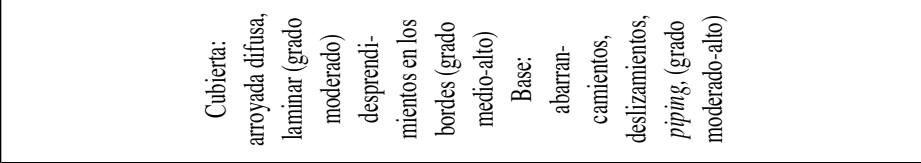 \\
\hline 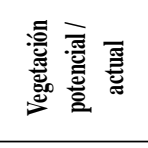 & 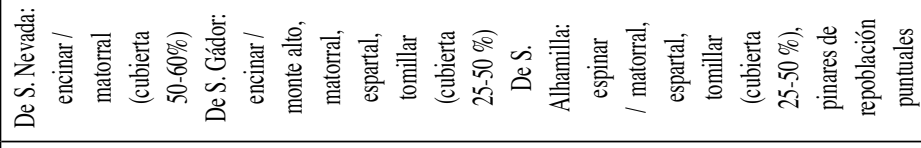 \\
\hline 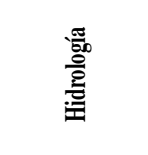 & 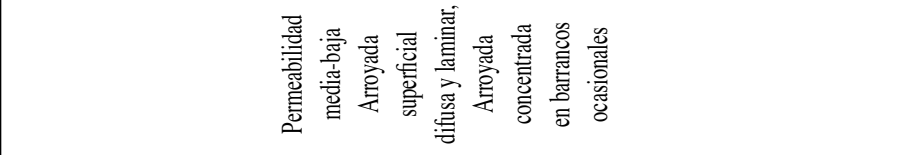 \\
\hline 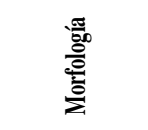 & 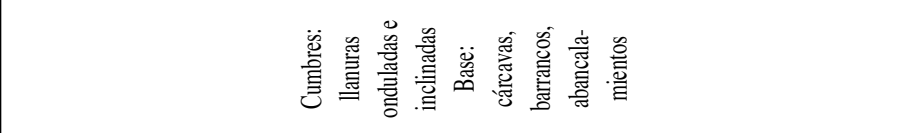 \\
\hline 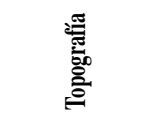 & 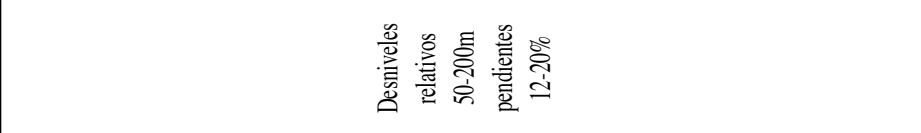 \\
\hline 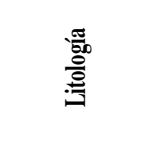 & 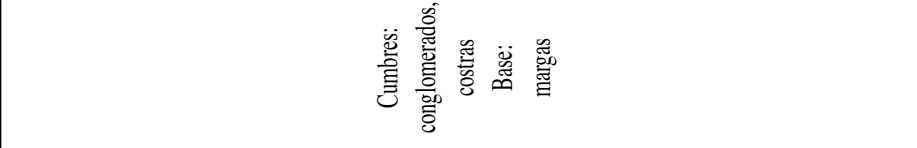 \\
\hline 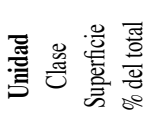 & 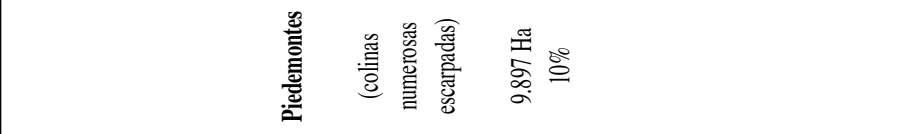 \\
\hline
\end{tabular}




\begin{tabular}{|c|c|c|}
\hline 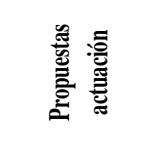 & 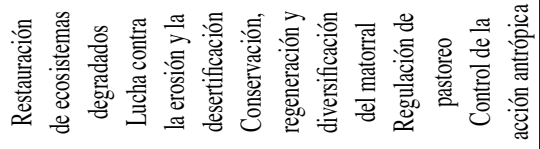 & 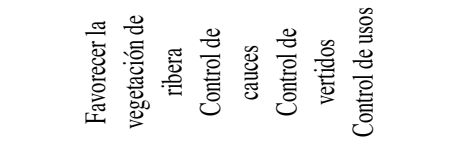 \\
\hline 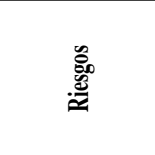 & 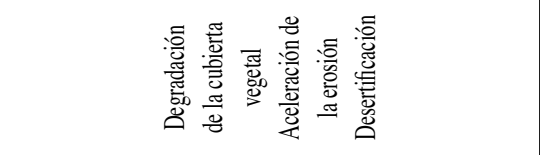 & 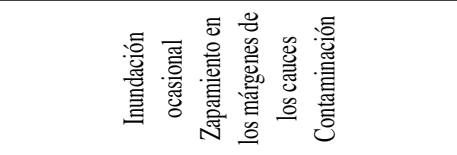 \\
\hline 总 & 密 & . \\
\hline 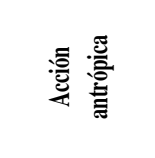 & 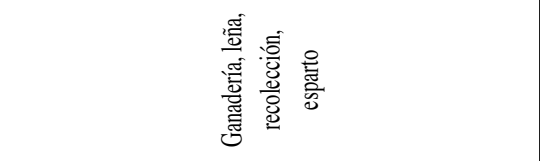 & 总况 \\
\hline 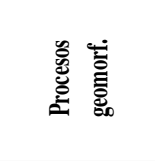 & 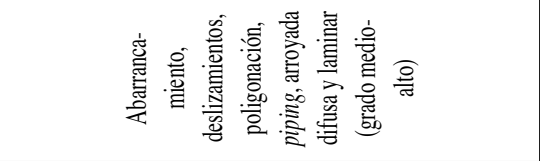 & 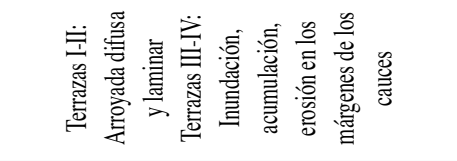 \\
\hline 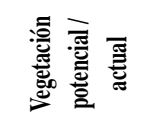 & 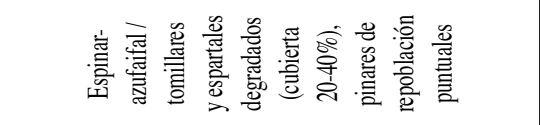 & 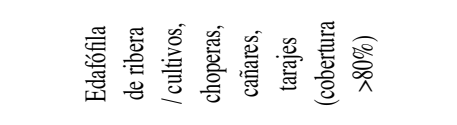 \\
\hline 営 & 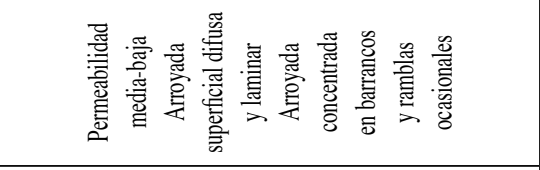 & 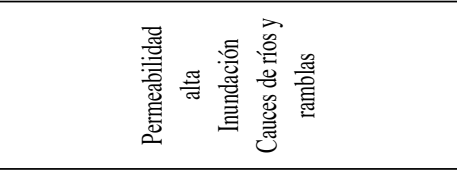 \\
\hline 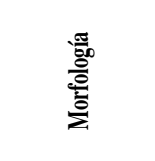 & 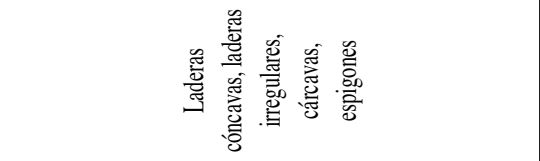 & 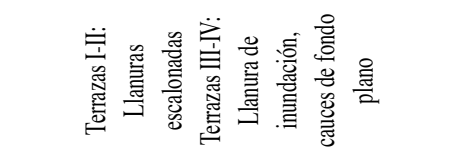 \\
\hline 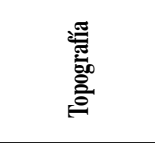 & 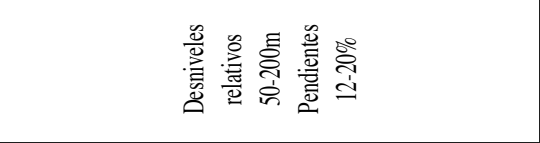 & 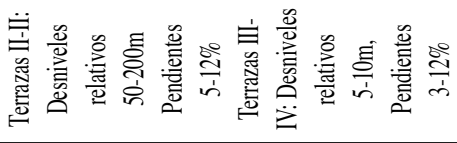 \\
\hline 䌟 & 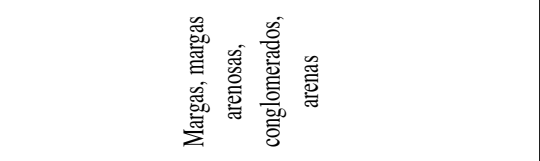 & 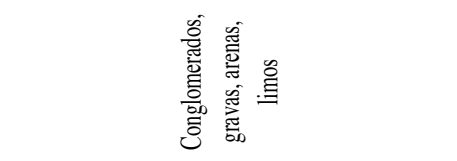 \\
\hline 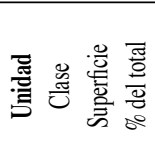 & 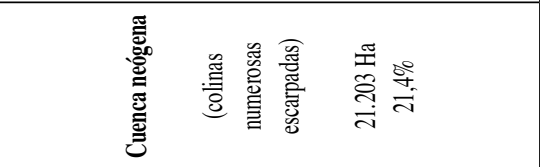 & 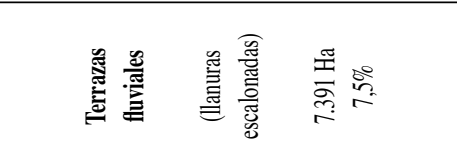 \\
\hline
\end{tabular}




\begin{tabular}{|c|c|}
\hline 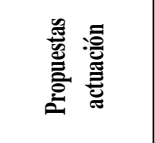 & 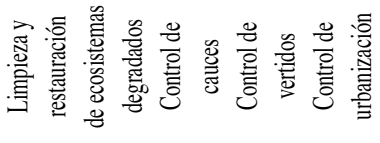 \\
\hline 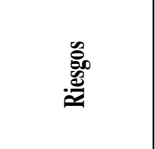 & 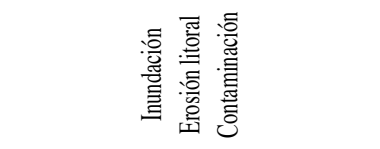 \\
\hline 㺃 & 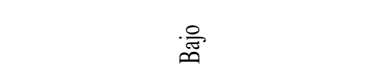 \\
\hline 搃衰 & 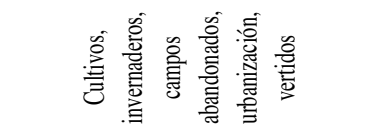 \\
\hline 总 & 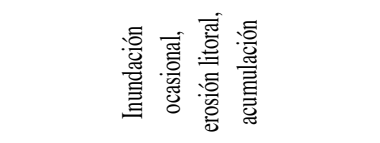 \\
\hline 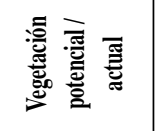 & 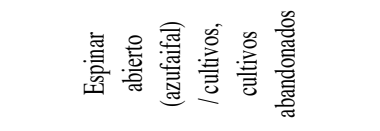 \\
\hline 営 & 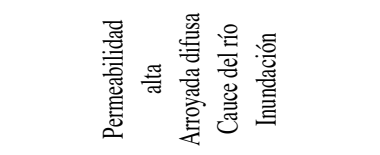 \\
\hline 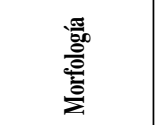 & 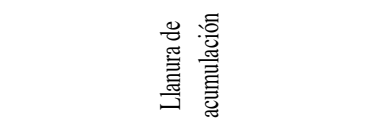 \\
\hline 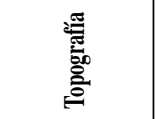 & 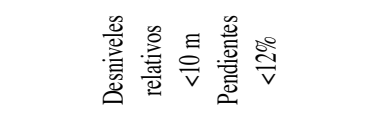 \\
\hline 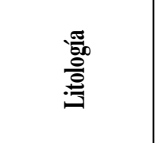 & 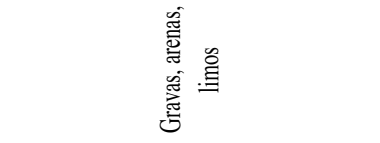 \\
\hline 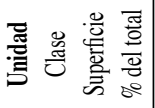 & 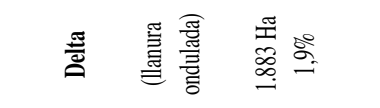 \\
\hline
\end{tabular}

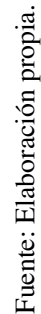




\section{BIBLIOGRAFÍA}

BRÜCKNER, H. (1986): “Man's impact on the evolution of physical environment in the Mediterranean Region in historical times", GeoJurnal, 13 (1), pp.7-17.

BRÜCKNER, H. y HOFFMANN, G. (1992): "Human-induced erosion processes in Mediterranean countries", Geoökoplus, 3, pp. 97-110.

BRUNNACKER, K. (1974): "Observaciones sobre las terrazas marinas y glacis de piedemonte en el Sudeste de España”, Estudios Geográficos, 130, pp. 133-140.

CAPEL, J.J. (1986): El clima de la provincia de Almería, $2^{\mathrm{a}}$ ed., Publicaciones Cajaalmería.

CENDRERO, A. et al. (1986): Mapa geocientífico de la provincia de Valencia, Diputación Provincial de Valencia, Universidad de Valencia, Universidad de Cantabria.

CHRISTIAN, C.S. y STEWART, G.A. (1958): "The concept of land units and lands systems", Proc. 9th Pacific Science Congress, pp. 74-81.

DÍAZ DE TERÁN, J.R. et al., (1991): Geomorfología y edafología de Guipúzcoa, Departamento de Urbanismo, Arquitectura y Medio Ambiente de la Diputación Foral de Guipúzcoa.

DÍAZ GARRETAS, B., ASENSI, A., FERRE, E., VALLE, F. (1996): Estudio fitosociológico integral, modelos de evaluación biológica y restauración de la vegetación en un territorio amenazado por la desertificación. Cuenca del río Andarax (Almería, España), Proyecto becado por la fundación "RAMON ARECES", (policopiado).

DUMAS, B. (1977): Le Levant espagnol. La génese du relief, Univ. de Paris XII, 520 pp.

DUMAS, B., GUEREMY, P., LHENAFF, R., RAFFY, J. (1978): “Geomorphologie et neotectonique dans la region d'Almeria (Espagne du Sud-Est)", Travaux R.C.P. 461, París, pp. 123-170.

FERRE BUENO, E. (1997) a: "Unidades de diagnóstico para la evaluación de la peligrosidad geomorfológica en el valle del Andarax (prov. de Almería)", Baetica, 19, I, pp. 111-134.

FERRE BUENO, E. (1997) b: "Estados erosivos en la cuenca media del río Andarax" Cuadernos geográficos, 27, pp.153-169.

FERRE BUENO, E. y SENCIALES GONZÁLEZ, J. M. (1994) a: Elaboración de la cartografía y delimitación de unidades geomorfoedáficas del Parque Natural "Montes de Málaga", Proyecto financiado por la A.M.A. Junta de Andalucía, (policopiado).

FERRE BUENO, E. y SENCIALES GONZÁLEZ, J. M. (1994) b: "Unidades ambientales aplicadas al control de impactos: el caso de Torremolinos (prov. de Málaga)", Baetica, 16, pp. 44-81.

FRANCÉS, E., CENDRERO, A., MOREY, M. (1989): “Un modelo de evaluación del territorio para la planificación, con base geomorfológica, aplicado a la vertiente cantábrica", Cuaternario y Geomorfología, pp. 106-115.

FOMBOTE, J. Mª y VERA, J. A. (1983): "La Cordillera Bética”, en: I.G.M.E. (eds.): Geología de España, Libro Jubilar de J.M. ríos, I.G.M.E., Madrid, vol. II, pp. 205-342. 
GOY, J.L. et al. (1992): "Morfological response to an intraplate transcurrent zone (Eastern Betiques, SE Spain). Quaternary Basins Types and Neotectonics", en: MONER, OWEN, STEWART, VITA-FINEZI, (eds.): Neotectonic Recent Advances, London, Abbst. vol. 25.

GOY, J.L., ZAZO, C. y RODRÍGUEZ VIDAL, J. (1994): “Cordilleras Béticas e Islas Baleares", en: GUTIERREZ ELORZA, M. (coord.) Geomorfología de España, Ed. Rueda, Madrid, pp. 123-157.

GOY, J.L. y ZAZO, C. (1983): “Los piedemontes cuaternarios de la región de Almería (España), análisis morfológico y relación con la neotectónica", Actas de la VI Reunión del Grupo Español de Trabajo del Cuaternario, Cuadernos do Laboratorio Xeolóxico de Laxe, 5, pp. 397-419.

HARVEY, A. (1987): "Patterns of Quaternary aggradational and disecctional landform in the Almería region, southeast Spain: a dry-region, tectonical active landscape", Die Erde, 118, pp. 193-215.

HARVEY, A. (1990): "Factor influencing Quaternary alluvial fan develpment in southeast Spain", in: RAKKOCKY, A.H., and CHURCH, M.J. (eds.): Alluvial fans a field approach, Wiley \& Sons, New York, pp. 247-269.

JACQUIN, J.P. (1970): Contribution a l'étude geologique et miniere de la sierra de Gágor (Almería, Espagne), Thèse, Nantes, 501 p.

MAPA GEOLOGICO DE ESPAÑA (MAGNA), (1983), Memoria de las Hojas 1043, 1044, 1045, 1029, 1030, 1059, I.G.M.E..

MONTENAT, CH. et al., (1990): "Geodynamic evolution of the neogene intramontane basins S and SE Spain)", Paleontologia y Evolució, 2, pp. 7-16.

RIVAS MARTÍNEZ, S. (1995): “Clasificación bioclimática de la Tierra”, Folia Botánica Matritensis, 16.

ROHDENBURG, H. y SABELBERG, U. (1984): "Las costras calizas y su valor climático testimonial. Nuevas observaciones en España y África del Norte”, Estudios geográficos, 174, pp. 215-237.

SANZ DE GALDEANO, C. (1983): "Los accidentes y fracturas principales de las Cordilleras Béticas, Estudios Geológicos, 39, pp. 157-165.

SANZ DE GALDEANO, C. y ALFARO, P. (2004): "Tectonic significance of the presen relief of Betic Cordillera", Geomorphology, 63, pp. 175-190.

SCHULTE, L. (1998): "Respuesta de la dinámica fluvial a los cambios climáticos en el sureste peninsular”. En: GÓMEZ ORTIZ, A.: Investigaciones recientes de la Geomorgología española, pp. 433-444.

SCHULTE, L. (2002): Evolución cuaternaria de la Depresión de Vera y de Sorbas oriental (SE - Península Ibérica), Universidad de Barcelona, $251 \mathrm{p}$.

VAN ZUIDAM, R. A. y VAN ZUIDAM CANCELADO, F. I. (1979): Terrain analysis and classification using aerial photographs. A geomorphological approach, ITC Textbook of Photo-Interpretatation VII-6, Enschede, The Netherlands. 